\title{
Seismic Response and Vibration Reduction Analysis of Suspended Structure under Wave Passage Excitation
}

\author{
Wenhua Cai $\mathbb{D}^{1,2}$ Bujun Yu, ${ }^{1,}$ Fajong Wu, ${ }^{1}$ and Jianhua Shao ${ }^{3}$ \\ ${ }^{1}$ Department of Civil Engineering, Yancheng Institute of Technology, Yancheng, China \\ ${ }^{2}$ Department of Civil Engineering, University of Birmingham, Birmingham, UK \\ ${ }^{3}$ School of Civil Engineering and Architecture, Jiangsu University of Science and Technology, Zhenjiang, China \\ Correspondence should be addressed to Wenhua Cai; caiwenhua10@163.com
}

Received 10 December 2019; Revised 26 June 2020; Accepted 30 June 2020; Published 21 July 2020

Academic Editor: Lyan-Ywan Lu

Copyright ( $\odot 2020$ Wenhua Cai et al. This is an open access article distributed under the Creative Commons Attribution License, which permits unrestricted use, distribution, and reproduction in any medium, provided the original work is properly cited.

In order to study the influence of traveling wave effect on the seismic response and damping effect of suspended structure, a series of shaking table tests of the 1:20 suspended structure have been carried out to compare and analyze the dynamic responses of suspended structures under two points and a consistent input. The vibration damping effect and vibration reduction law of suspended structure are discussed at different apparent wave velocity and in the different connection. The research shows that the damping suspended structure has a good damping effect, and the amplitude reduction of the top displacement peak response is up to $15 \%$, which corresponds to smaller apparent velocities. Moreover, the upper bound of the maximum acceleration response at the structures' top under nonuniform input motions equals that of the uniform motion. However, there is a hysteresis in the acceleration response under wave travelling excitations, and the smaller the apparent wave velocity, the more obvious the hysteresis.

\section{Introduction}

The occurrence of earthquakes is random, and the propagation of ground motion is a complex process with variability in both time and space. In the past, when seismic design or research was carried out on structures, attention was often focused on the time-varying characteristics of ground motions, while the spatial characteristics of ground motions were hardly considered. This approach is desirable when the structural span is small, but when the span of the structure reaches a certain amount, such as 100 meters or even hundreds of meters, it is not advisable. Otherwise, the structural design would be unsafe. Existing research outcomes have shown that when the structural span is longer than $60 \mathrm{~m}$ and the apparent wave velocity is less than $500 \mathrm{~m} / \mathrm{s}$, the influence of spatial variation of ground motion on the structure needs to be considered $[1,2]$. Therefore, the problem of multipoint excitation should be considered while the seismic response analysis of many structures is made. However, at present, the research on the seismic response of multipoint excitation is still on the way, and a more reasonable theoretical system or design method has not been forward.

Due to the diversification of structural forms, the seismic responses of multipoint excitation are also different. Scholars at home and abroad focused on some large-span structures represented by some bridges [3-6] and then paid attention to some unique structures, such as arch trusses [7], arch dams [8], string support shell [9], cable dome [10, 11], long tunnel [12], and multitower and conjoined structure $[13,14]$. The seismic response study of multi- and highconcrete frame structures under multipoint excitation is less reported at home and abroad [15]. Rambabu studied the traveling wave effect on a simple one-story frame seismic response and pointed out that "even if the short-span structure should not ignore the traveling wave effect," it can be seen that it is necessary to study the seismic response of the frame structure under multipoint excitation.

The emphasis laid on building environmental conditions has contributed to the diversity of architectural forms. In the 1950s, a new type of building structure system, a suspended building structure, had emerged. Its morphologicalstrategies 
and structural techniques could achieve the following goals: land saving, material saving, little damage to the environment, and high degree of industrialization and assembly. Thisstructural system can fully reflect the concept and spirit of "green" in the entire life cycle of the building. Therefore, the building known as the "green building form" [16] has increasingly attracted the attention of architects and engineers.

According to the engineering practice of the existing suspended building structure, combined with the classification of the suspension structure by Schuler [17], the suspended building structure is divided into two categories: the core-tube suspended building structure [18-20] and the megaframe suspended building structure [21, 22]. The megaframe suspended structure has attracted much attention due to the flexibility of its architectural function layout and design. At present, the research on this structural system is not mature enough. According to the definition of JGJ32010 [23] "Technical Regulations for Concrete Structures of High-Rise Buildings," the structure belongs to "complex high-rise building structure," and its span is usually greater than $60 \mathrm{~m}$, so it is necessary to consider multipoint excitation when seismic response analysis is performed.

In this paper, the simulated shaking table tests of the $1: 20$ scale model structure are carried out for two kinds of megaframe suspended structures, whose primary and secondary structures are connected by rigid connecting rods and viscous dampers, respectively. The dynamic response of the two model structures under seismic excitation considering the traveling wave effect is analyzed. The damping effect of the suspended model structure with viscous dampers is analyzed and discussed.

\section{Experimental Program}

2.1. Test Model Design. The test model was designed in accordance with the Code for Seismic Design of Buildings [24], Specification for Seismic Test of Buildings [25], and Technical Regulations for Concrete Structures of High-Rise Buildings (JGJ3-2010) considering the limited size and capacity of the shaking table and the effects of the similitude law. The structural model is a 10-storey megaframe suspended structure with a plane size of $4.48 \mathrm{~m} \times 0.63 \mathrm{~m}$ and a total height of $2.28 \mathrm{~m}$. The suspended floors are $3.14 \mathrm{~m} \times 0.87 \mathrm{~m}$ plane and are $0.03 \mathrm{~m}$ thick. The four corners of the suspended floors are reserved with a gap of $0.1 \mathrm{~m} \times 0.19 \mathrm{~m}$. The 9 th and 10 th floors of the structure are the floors where the megaframe hanging beams are located. The two ends of the model structure are provided with giant columns, between the two giant columns, and the suspended floors are arranged, as shown in Figure 1. The suspended floor of each layer is suspended by six steel cables fixed on the hanging beam, and a particular gap is left between each suspended floor and the giant column for changing the connection mode of the primary and secondary structures (the two connection methods are shown in Figure 2).

The structural model was made of galvanized steel wires and particulate concrete in a 1:20 scale. The compressive strength of concrete measured by the cube and prismatic test block of materials of the same batched and cured alongside the model was 9.4 MPa. The yield strength of the galvanized steel wires was $240 \mathrm{MPa}$, and the modulus of elasticity for the steel wires was $2.00 \times 10^{5} \mathrm{MPa}$. The viscous dampers used in the suspended structure were designed and manufactured by the Taylor Company of the United States. It is a linear speed damper, with $2005 \mathrm{~N}$ maximum damping force and $5 \mathrm{kN} \cdot \mathrm{s} / \mathrm{m}$ damping coefficient, and $102 \mathrm{~mm}$ maximum travel. The geometry and shape of the viscous damper are shown in Figure 2.

2.2. Model Similarity Rate and Weight Scheme. In order to genuinely reflect the dynamic characteristics of the prototype structure, the similarity parameters of the experimental model were designed according to the similar theory. The inertial force, gravity, and resilience of the prototype structure and the model structure satisfy the Cauchy condition [26, 27]:

$$
\frac{S_{E}}{S_{a} S_{\rho}}=S_{l},
$$

where $S_{E}$ is the similarity ratio of the elastic modulus, $S_{a}$ is the similarity ratio of the acceleration, $S_{\rho}$ is the similarity ratio of the gravity density, and $S_{l}$ is the geometric similarity ratio.

The scale ratio of the test model was taken as $S_{l}=1: 20$ considering the test conditions such as transportation and hoisting of the model. The similarity ratio of the elastic modulus is $S_{E}=1 / 5$ according to the test results of the materials used in the model. The similarity ratio of gravity density was assumed $S_{\rho}=2.67$. The above three parameters were put into equation (1), and the similarity ratio of the acceleration was $S_{a}=1.5$. Table 1 shows the similarity relationships.

The weighting scheme of the model structure is that each layer of the giant columns is added with a weight of $160 \mathrm{~kg}$ (a total of 8 weight mass), each layer of the hanging beam is added with a weight of $240 \mathrm{~kg}$ (a total of 12 weight mass), and each layer of suspended floor is covered with a weight of $240 \mathrm{~kg}$ (a total of 12 weight mass). By adding masses, the mass ratio of the main structure and secondary structure is $1: 0.54$. The manual mass is made of counterweight mass and is fixed to the main structure and the suspended floors with foam glue. The weighting scheme is shown in Figure 3. A photo of the structural model completed installation is shown in Figure 4.

2.3. Testing Loading Protocol. The shaking table is a computer-controlled, midsized $(2 \mathrm{~m} \times 2 \mathrm{~m})$ earthquake simulation system. The system is a triaxial testing system with full six-degree-of-freedom control. The main specifications of the system are shown in Table 2 . Two identical shaking table systems were used to explore the dynamic response of the structure under wave passage excitation. The wave passage excitation was realized by the phase difference of seismic excitation. 


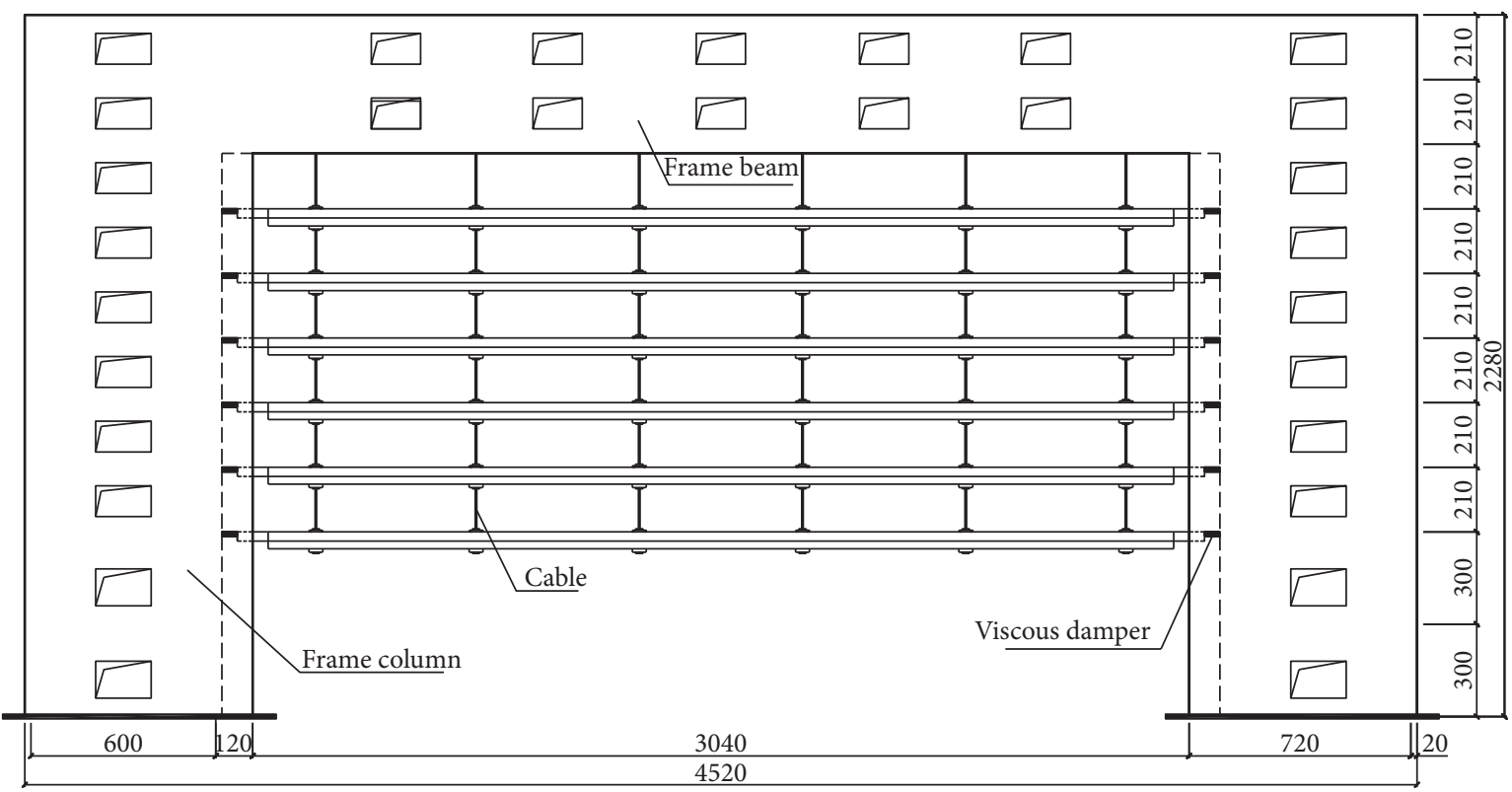

(a)

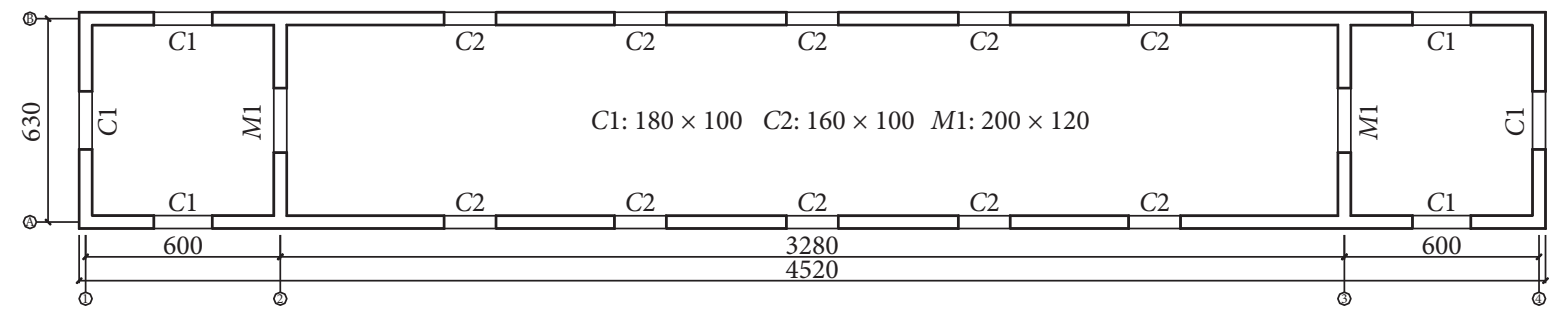

(b)

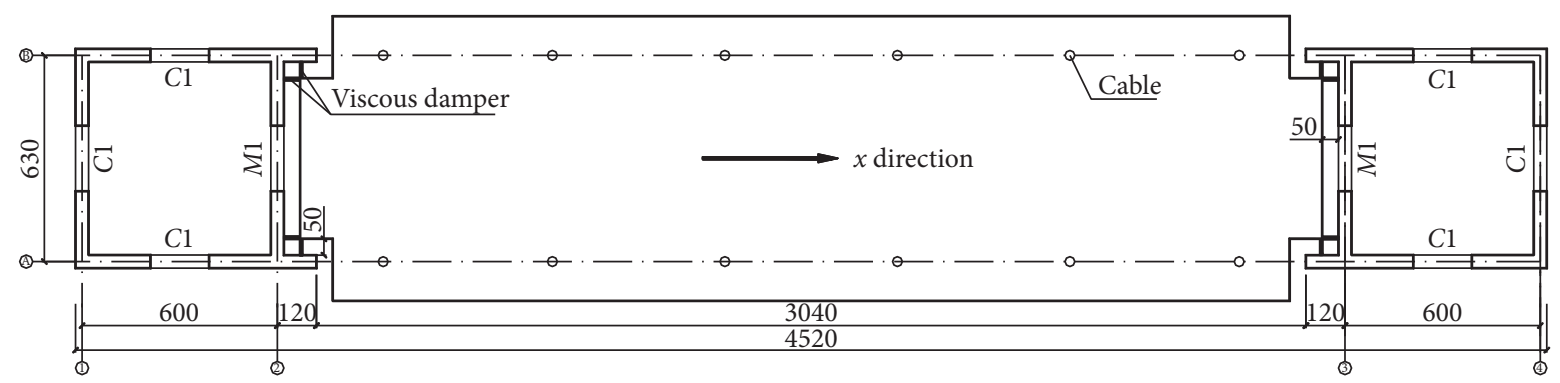

(c)

Figure 1: Schematic diagrams of structural plane and elevation. (a) Front view. (b) Frame-beam floor plane. (c) Suspended floor.

In the experiment, the El Centro wave of the 1940 Imperial Valley earthquake (M6.9), the Taft wave of the 1952 Kern County earthquake (M7.5), and the representative artificial wave were selected as input data of the shaking table (Table 3 lists the characteristic parameters of the selected seismic wave), and input along the long span of the structure. The duration and time interval of the seismic wave were scaled and adjusted according to the similarity relationship and the test requirements. The acceleration response spectrum with a damping ratio of 0.05 after time adjustment is shown in Figure 5.

The experiment studied the performance of the structure in the elastic state. Therefore, the basic seismic acceleration was designed to test under the five load levels of 7 frequent, 8 frequent, 9 frequent, 7 rare, and 8 rare earthquakes in the $0.15 \mathrm{~g}$ area (GB 50011-2010, 2010). The design peak value of table acceleration increased as follows: $0.0525 \mathrm{~g}, 0.105 \mathrm{~g}$, $0.210 \mathrm{~g}, 0.330 \mathrm{~g}$, and $0.600 \mathrm{~g}$. White noise excitation was used before the start of the test and after the end of each load level to measure the dynamic characteristics and their changes.

In order to investigate the dynamic response of the model structure under different apparent wave velocities, the apparent wave velocities of this experiment were taken at $300 \mathrm{~m} / \mathrm{s}, 500 \mathrm{~m} / \mathrm{s}$, and $800 \mathrm{~m} / \mathrm{s}$, respectively, and the traveling wave effect was realized by the method of phase difference of seismic excitation. 


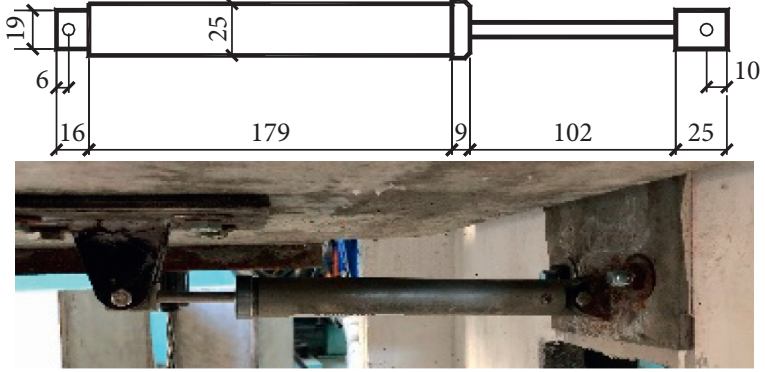

(a)

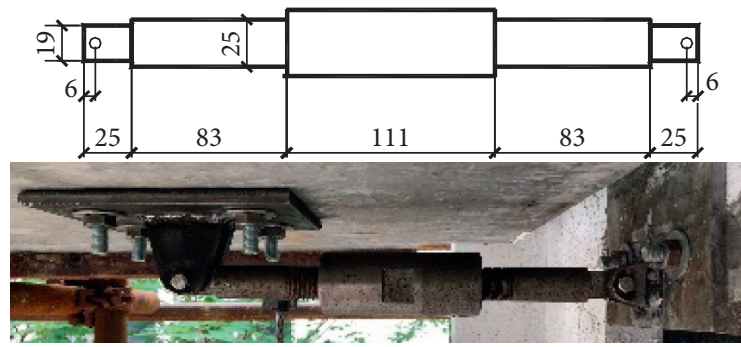

(b)

Figure 2: Schematic diagrams of two types of connections. (a) Viscous damper. (b) Rigid connecting rod.

TABLE 1: Similarity coefficient of the test model.

\begin{tabular}{lcc}
\hline Physical quantity & Dimensions & Ratio of similitude \\
\hline Length & $L$ & $S_{l}=1 / 20$ \\
Elastic modulus & $F L^{-2}$ & $S_{E}=1 / 5$ \\
Stress & $F L^{-2}$ & $S_{\sigma}=1 / 5$ \\
Gravity density & $F T^{2} L^{-1}$ & $S_{\rho}=2.67$ \\
Time & $T$ & $S_{T}=1 / 5.48$ \\
Poisson ratio & - & $S_{v}=1$ \\
Acceleration & $L T^{-2}$ & $S_{a}=1.5$ \\
Velocity & $L T^{-1}$ & $S_{v}=0.269$ \\
Frequency & $T^{-1}$ & $S_{f}=5.38$ \\
Strain & - & $S_{\varepsilon}=1$ \\
Stiffness & $F L^{-1}$ & $S_{k}=1 / 100$ \\
\hline
\end{tabular}

2.4. Instrumentation. According to the purpose of the test and the symmetry of the model structure, 12 horizontal acceleration sensors, 5 horizontal displacement laser sensors, and several strain gauges were mounted on the model to measure the acceleration and displacement response. This test equipment was mainly laid on the suspended floors, at the top of the structure, in the midspan and end of the hanging beam, and bottom of the giant columns, and the specific arrangement of the acceleration and displacement sensors is shown in Figure 6.

\section{Experimental Results and Discussion}

3.1. Structural Dynamic Characteristics. Under the seismic input of each case, the main structure of the two model structures (the structure with damper connection called damping suspended structure and the structure with rigid connecting rod connection called common suspended structure) has no cracks from beginning to end, and the steel cable has no signs of damage. It could be determined that during the test, the structure was always in a flexible working state.

The white noise was used to sweep the structure before and after the seismic input in each case. The first three-order natural vibration frequencies of the structure in the $x$-direction are shown in Table 4.

It can be seen from Table 3 that the first three damping ratios of the damping suspended structure were 9.254, 5.879, and $3.362 \%$, respectively, while the first three damping ratios of the common suspended structure were $2.301,0.813$, and
$0.710 \%$, respectively. Therefore, the damping ratio of two model structures decreased as the natural frequency went up. Moreover, the damping ratio of the suspended damping structure was significantly larger than that of the common suspended structure.

The first three-order natural frequencies of the suspended damping structure were significantly smaller than those of the common suspended structure, especially the first order. It shows that the suspended damping structure connected by the viscous dampers was softer than the common suspended structure connected by the rigid connecting rods. The setting of the viscous dampers increased the damping ratio of the suspended structure.

3.2. Displacement Response. The displacement of the top of the main structure and the relative displacement between the suspended floors and the main structure are key indicators for determining the damping performance of the suspended structure. In addition to the peak of the seismic response, it is also necessary to pay attention to the difference in response of the two model structures at different apparent wave velocities. Table 5 shows the peak displacement response of the two model structures at different apparent velocity under the 9 frequent earthquakes. The amplitude reduction [28] in Table 4 can be calculated by the following formula:

$$
k=\frac{R_{1}-R_{2}}{R_{1}} \times 100 \% \text {, }
$$

where $R_{1}$ is the peak response of the common suspended structure and $R_{2}$ is the peak response of the damping suspended structure.

The influence rate of the structural response was introduced to clarify the influence of the traveling wave effect on the seismic response of the structure. The influence rate $\alpha$ in Table 4 can be expressed by the following formula [28]:

$$
\alpha=\frac{S_{m-} S_{u}}{S_{u}} \times 100 \%
$$

where $S_{m}$ is the peak response of the two structure models at each apparent wave velocity and $S_{u}$ is the peak response of the two structure models in uniform excitation.

It can be seen from Table 5 that compared with the common suspended structure, the top displacement peak 


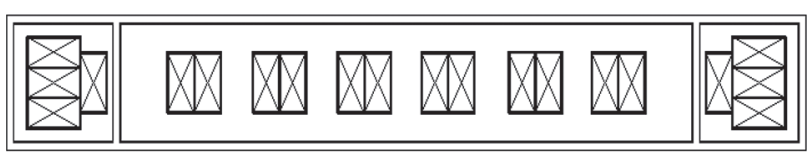

(a)

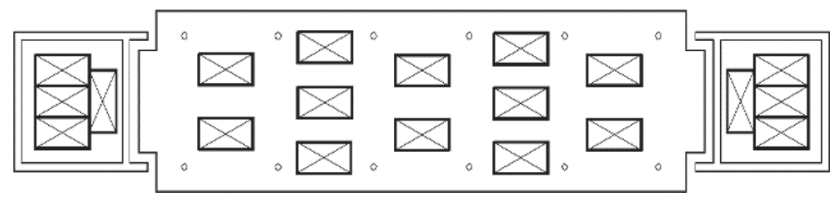

(b)

Figure 3: Weight scheme of the test model. (a) The primary structure. (b) Suspended floors.

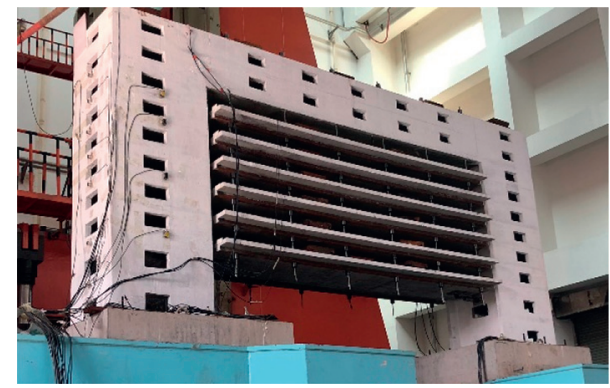

Figure 4: Experiment mode.

TABLE 2: Specifications of the earthquake simulation system.

\begin{tabular}{|c|c|c|c|}
\hline \multicolumn{2}{|c|}{ Physical quantity } & \multicolumn{2}{|c|}{ Parameter } \\
\hline \multirow{3}{*}{\multicolumn{2}{|c|}{$\begin{array}{l}\text { Shaking table dimensions } \\
\text { Maximum specimen weight } \\
\text { Operating frequency range }\end{array}$}} & \multicolumn{2}{|c|}{$2 \mathrm{~m} \times 2 \mathrm{~m}$} \\
\hline & & \multicolumn{2}{|c|}{$100 \mathrm{kN}$} \\
\hline & & \multicolumn{2}{|c|}{$0.4-50 \mathrm{~Hz}$} \\
\hline \multicolumn{2}{|c|}{ Vibration waveform } & Seismic wave, & $\begin{array}{l}\text { random wave, sine } \\
\text { wave }\end{array}$ \\
\hline \multicolumn{2}{|l|}{ Drive mode } & Electr & draulic \\
\hline Direction & ax. amplitude & Max. velocity & Max. acceleration \\
\hline Horizontal $X$ & $\pm 125 \mathrm{~mm}$ & $\pm 500 \mathrm{~mm} / \mathrm{s}$ & $\pm 2.0 \mathrm{~g}$ \\
\hline Horizontal $Y$ & $\pm 125 \mathrm{~mm}$ & $\pm 500 \mathrm{~mm} / \mathrm{s}$ & $\pm 2.0 \mathrm{~g}$ \\
\hline Vertical $Z$ & $\pm 100 \mathrm{~mm}$ & $\pm 500 \mathrm{~mm} / \mathrm{s}$ & $\pm 2.0 \mathrm{~g}$ \\
\hline
\end{tabular}

TABLE 3: Characteristics of earthquake motions.

\begin{tabular}{lccc}
\hline Seismic wave & PGA $\left(\mathrm{m} / \mathrm{s}^{2}\right)$ & PVG $(\mathrm{m} / \mathrm{s})$ & Time interval $(\mathrm{s})$ \\
\hline El Centro & 3.417 & 0.335 & 0.02 \\
Taft & 1.759 & 0.177 & 0.02 \\
Artificial wave & 3.5 & 0.997 & 0.02 \\
\hline
\end{tabular}

response of the damping suspended structure had different degrees of reduction. For example, under the action of the Taft wave, the amplitude reduction was $10.37 \%$ when the excitation was uniform. However, when the apparent wave velocity was $500 \mathrm{~m} / \mathrm{s}$, the amplitude reduction was $15.74 \%$. The amplitude reduction $k$ in Table 5 ranged from $0.83 \%$ to $15.74 \%$. These data show the suspended structure installed dampers with good seismic performance and a certain damping effect.

Observing the change of the influence rate $\alpha$ and comparing the peak displacement response of the main structure's top under the uniform excitation and different apparent wave velocities, we can know that there was no obvious law regardless of the common suspended structure or damping suspended structure. It indicated that as the apparent wave velocity dropped, the peak displacement of the main structure may increase or decrease. For example, under the action of artificial waves of 9 frequent earthquakes, the top displacement response of the damping suspended structure was $2.973 \mathrm{~mm}$, $3.162 \mathrm{~mm}, 2.437 \mathrm{~mm}$, and $2.658 \mathrm{~mm}$ at the uniform excitation, $800 \mathrm{~m} / \mathrm{s}, 500 \mathrm{~m} / \mathrm{s}$, and $300 \mathrm{~m} / \mathrm{s}$, respectively. No regularity could be seen, but when the apparent wave velocity was $800 \mathrm{~m} / \mathrm{s}$, the peak displacement response of the damping suspended structure was greater than the rest. It showed that the peak displacement response of the two model structures was the largest at $800 \mathrm{~m} / \mathrm{s}$ apparent velocity, which was the most unfavourable for the structure. In addition, under the excitation of different seismic waves, the damping effect was slightly different. Compared with the value of the amplitude reduction, the damping effect under the Taft wave was the best, the amplitude reduction was $6.19 \% \sim 15.74 \%$, the damping effect under the artificial wave was second, and the damping effect under the El Centro wave was the worst. However, the value of the displacement peak response under the artificial wave was smaller than under the El Centro wave and Taft wave. This indicates that the damping effect was related to the spectral characteristics of the input seismic wave, and the artificial wave more likely excited the vibration of the suspended floors to reduce the displacement response of the main structure. Therefore, in the design of damping suspended structure, damper optimization should be carried out for different site categories and design earthquake groups to better exert the vibration reduction and energy consumption of the system.

The suspended floors were recorded as 1 6 from bottom to top. Figure 7 shows the relative displacement between suspended floors (first suspended floor and top suspended floor) and main structure under 9 frequent and 8 rare earthquakes.

It can be seen from Figure 7 that the relative displacement between the suspended floors and the main structure of the damping suspended structure was significantly larger than that of the common suspended structure, indicating that the suspended floors' swing amplitude of the damping suspended structure was larger than that of the common suspended structure. The swing of the damping suspended structure contributes to energy consumption and vibration reduction.

Whether it was the common suspended structure or the damping suspended structure, the relative displacement between the primary and secondary structures under the 8 rare earthquakes was more than 9 frequent earthquakes. It indicated that the larger the input of 


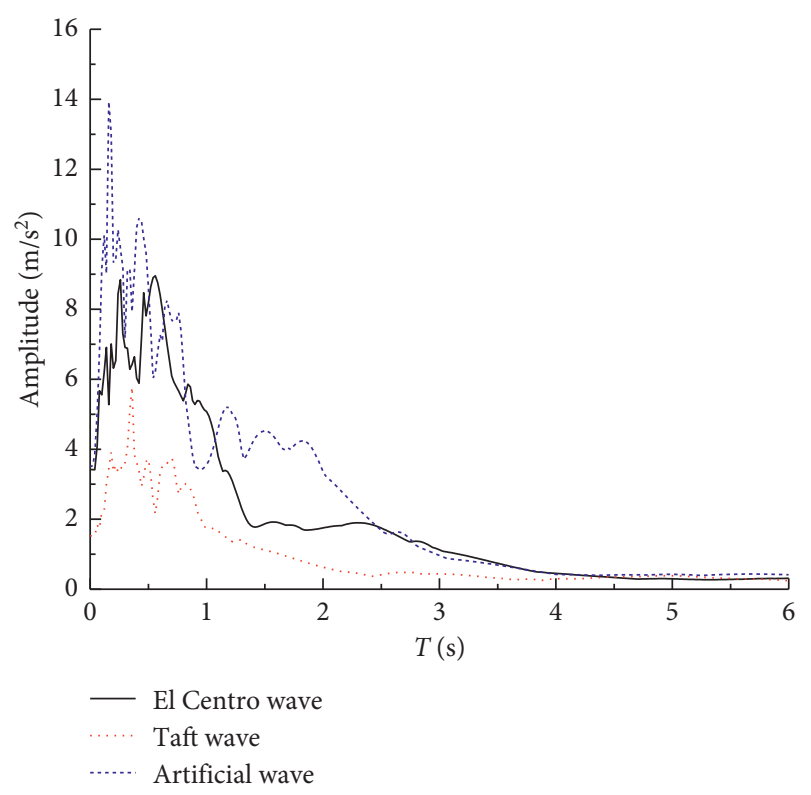

Figure 5: Acceleration response spectrum of three waves.

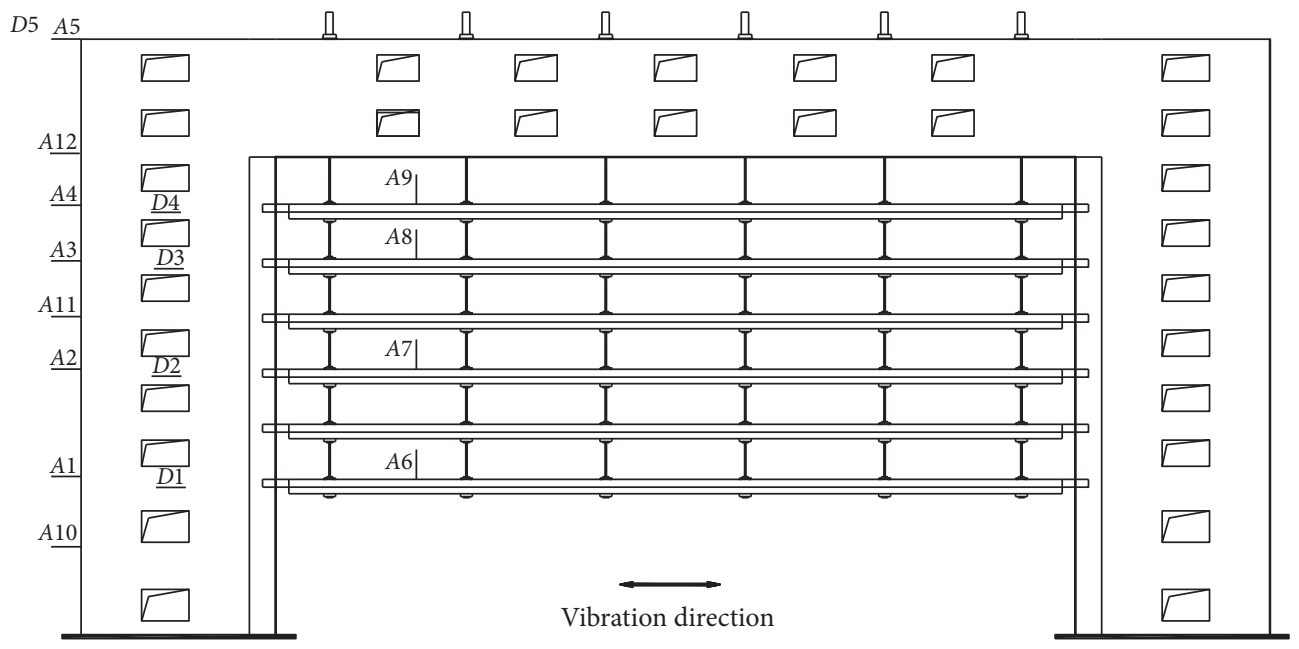

Figure 6: Layout of the displacement and acceleration sensors.

TABLe 4: Frequency and damping ratio of the model.

\begin{tabular}{lcccr}
\hline \multirow{2}{*}{ Mode shape } & \multicolumn{2}{c}{ Conventional suspended structure } & \multicolumn{2}{c}{ Damping suspended structure } \\
& Frequency $(\mathrm{Hz})$ & Damping ratio (\%) & Frequency $(\mathrm{Hz})$ & Damping ratio $(\%)$ \\
\hline 1 & 5.21 & 2.301 & 1.50 & 9.254 \\
2 & 10.74 & 0.813 & 3.71 & 5.879 \\
3 & 12.24 & 0.710 & 6.24 & 3.362 \\
\hline
\end{tabular}

seismic energy, the larger the relative displacement response of the model structure.

It can also be seen from Figure 7 that under different apparent wave velocities, there was no discernible regularity to the relative displacement between the primary and secondary structures. It may be because the seismic wave energy and spectral characteristics input during the test were different and the motion response of the main structure was inconsistent. The suspended floors were lagging behind the main structure due to the flexible damping, and the movement of the suspended floors interacted with each other, which caused the movement of the suspended floors to be very complicated and had many influencing factors. However, by carefully comparing the graphs, it can be found that the relative displacement between the primary and secondary structures of the two model structures under 9 frequent earthquake of the El Centro wave was larger than that of other apparent wave velocities and uniform 
TABLE 5: Displacement of the main structures' top.

\begin{tabular}{lcccccccc}
\hline Seismic input & Structure & Uniform excitation & $800 \mathrm{~m} / \mathrm{s}$ & $\alpha$ & $500 \mathrm{~m} / \mathrm{s}$ & $\alpha$ & $300 \mathrm{~m} / \mathrm{s}$ & $\alpha$ \\
\hline \multirow{3}{*}{ El Centro } & Common & 4.317 & 4.753 & $10.10 \%$ & 4.418 & $2.34 \%$ & 4.212 & $-2.43 \%$ \\
& Damping & 4.281 & 4.341 & $1.40 \%$ & 4.129 & $-3.55 \%$ & 3.916 & $-8.53 \%$ \\
& $k$ & $0.83 \%$ & $8.67 \%$ & - & $6.54 \%$ & - & $7.03 \%$ & - \\
\hline \multirow{3}{*}{ Taft } & Common & 4.947 & 4.912 & $-0.71 \%$ & 5.477 & $10.71 \%$ & 4.589 & $-7.24 \%$ \\
& Damping & 4.434 & 4.608 & $3.92 \%$ & 4.615 & $4.08 \%$ & 4.026 & $-9.20 \%$ \\
\hline \multirow{3}{*}{ Artificial wave } & $k$ & $10.37 \%$ & $6.19 \%$ & - & $15.74 \%$ & - & $12.27 \%$ & - \\
& Common & 3.346 & 3.396 & $1.49 \%$ & 2.525 & $-24.54 \%$ & 2.949 & $-11.86 \%$ \\
& Damping & 2.973 & 3.162 & $6.36 \%$ & 2.437 & $-18.03 \%$ & 2.658 & $-10.60 \%$ \\
\hline
\end{tabular}

Note: in addition to the \% data added in the above table, the remaining data units are all $\mathrm{mm}$. When $\alpha$ is positive, the response increases, and when it is negative, the response decreases.

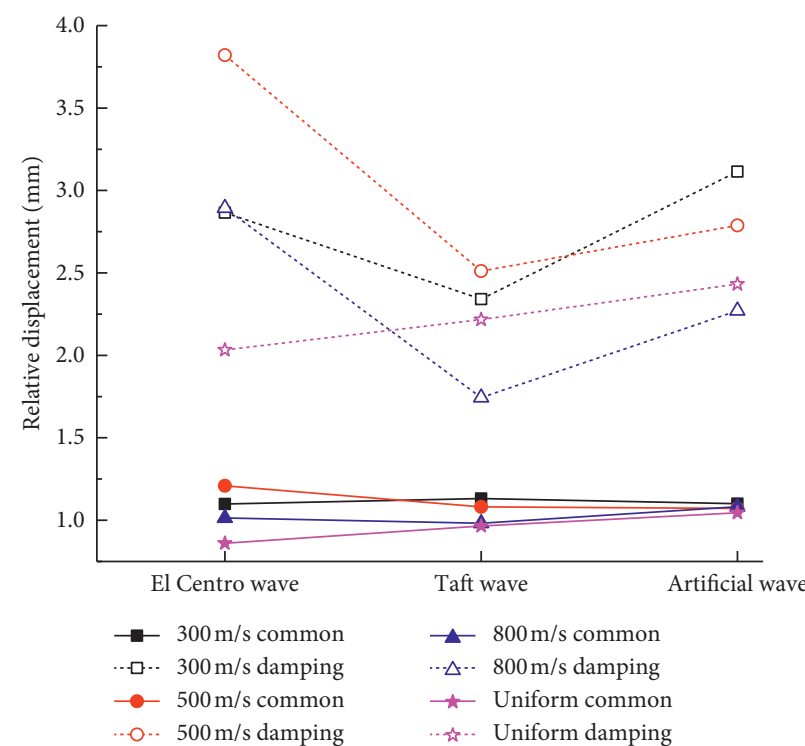

(a)

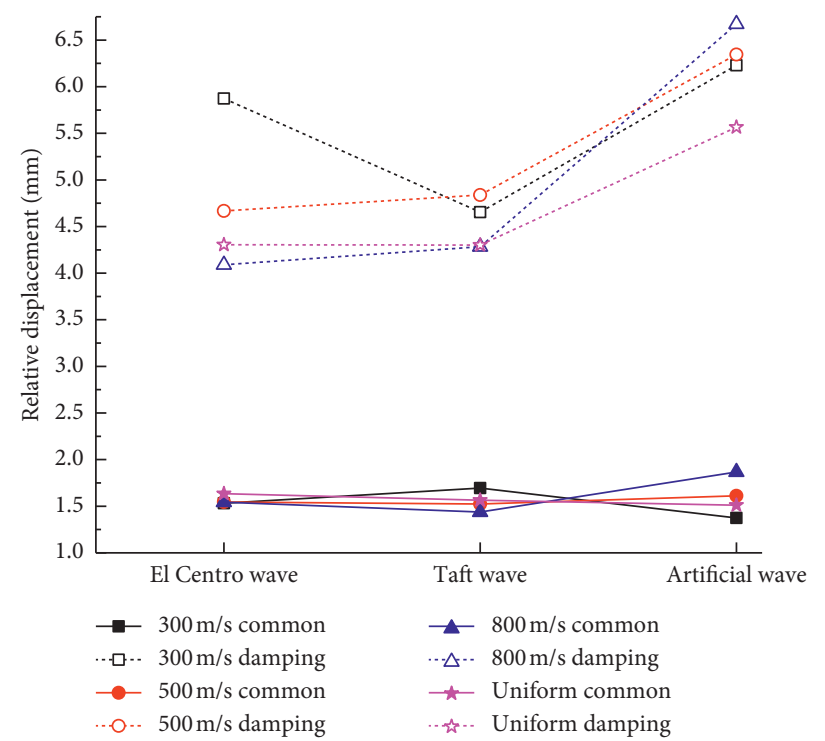

(c)

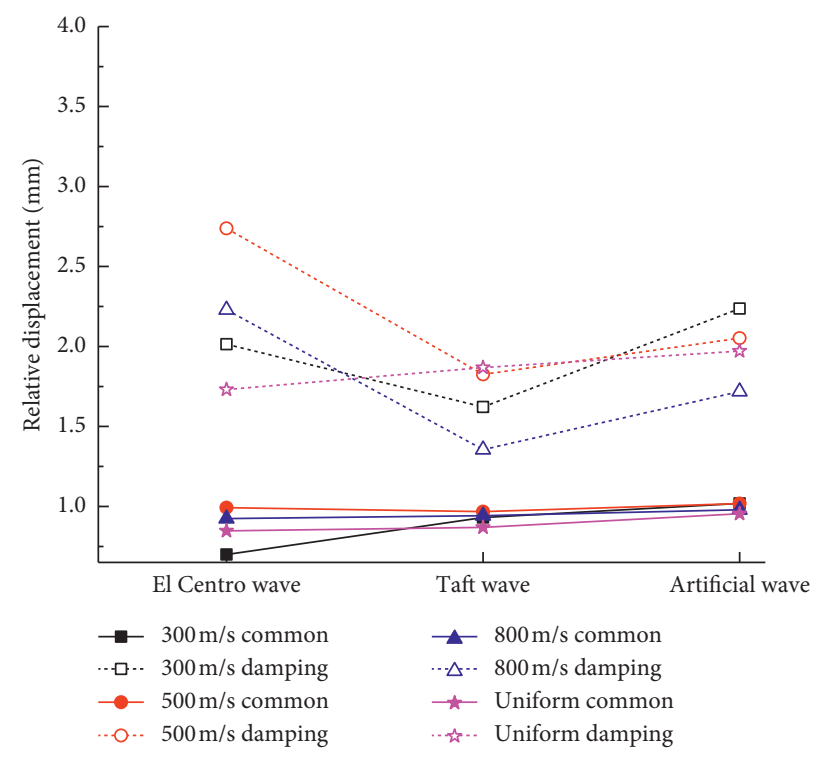

(b)

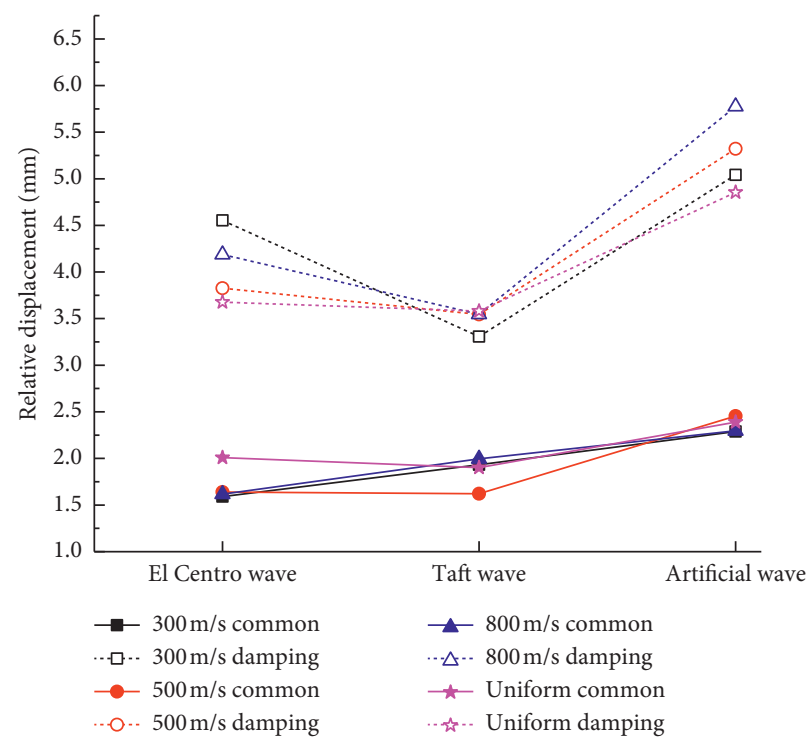

(d)

Figure 7: Relative displacement between suspended floors and main structure. (a) The first suspended floor under 9 frequent earthquakes. (b) The top suspended floor under 9 frequent earthquakes. (c) The first suspended floor under 8 rare earthquakes. (d) The top suspended floor under 8 rare earthquakes. 
excitation at apparent wave velocity of $500 \mathrm{~m} / \mathrm{s}$. While the apparent wave velocity was $800 \mathrm{~m} / \mathrm{s}$, the relative displacement between the primary and secondary structures of the two model structures under 8 rare earthquakes of the artificial wave was the largest. Comparing $a, b$ or $c$, and $d$ (Figure 7), it can be seen that the relative displacement of the first suspended floor under 9 frequent and 8 rare earthquakes was larger than that of the top suspended floor regardless of the damping suspended structure or common suspended structure.

3.3. Acceleration Response. The acceleration response of the primary and secondary structures was another vital indicator reflecting the dynamic response performance of the two model structures. In particular, the suspended floors as the main place where activities are carried out. When its response acceleration exceeds $0.25 \mathrm{~m} / \mathrm{s}^{2}$ (JGJ3-2010), it can cause discomfort.

Figure 8 shows the acceleration time-history curve of the main structures' top of the two model structures under the 9 frequent earthquakes.

As displayed in Figure 8, the top acceleration response of the two model structures slightly lagged behind the uniform excitation at each apparent wave velocity, and the smaller the apparent wave velocity, the more obvious the hysteresis. That is to say, under the action of the traveling wave effect, the response waveform of the model structure was similar to the response waveform of the uniform excitation, but the amplitude was different, and response lag came up. It can be considered that the vibration of each point of the structure was not synchronized due to the existence of the traveling wave effect, so that the vibration of each point changes greatly compared with the uniform excitation. If the apparent wave velocity was not large enough (the time difference can be neglected), the traveling wave effect cannot be ignored.

It can also be seen from Figure 8 that when the apparent wave velocity was $800 \mathrm{~m} / \mathrm{s}$, the peak acceleration response at the top of the common suspended model structure was less different from that under the uniform excitation. Under the El Centro wave and artificial wave, the peak acceleration value was slightly smaller than that of the uniform excitation. However, under the Taft wave, the peak acceleration value was slightly larger than that of uniform excitation. Moreover, the peak acceleration value of the apparent wave velocity $300 \mathrm{~m} / \mathrm{s}$ was significantly smaller than that of the apparent wave velocity $800 \mathrm{~m} / \mathrm{s}$ and uniform excitation. For the damping suspended model structure, as the apparent wave velocity increased, the peak acceleration response at the top of the structure was close to the response of the uniform excitation.

By comparing the results of the common suspended structure and the damping suspended structure under the action of three kinds of seismic waves in Figure 8, it can be seen that the peak acceleration response of the damping suspended structure was smaller than that of the common suspended structure under the condition of apparent wave velocity and uniform excitation. This reflects the good damping performance of the damping suspended structure.

Table 6 shows the peak response of the top suspended floor under the action of 9 frequent earthquakes, while Figure 9 shows the peak acceleration response of the top suspended floor under the apparent wave velocity of $500 \mathrm{~m} / \mathrm{s}$.

As can be seen from Table 6 that for the suspension damping model structure, the apparent wave velocity rose from $300 \mathrm{~m} / \mathrm{s}$ to $800 \mathrm{~m} / \mathrm{s}$ to uniform excitation and the peak acceleration response of the top suspended floor gradually increased and was quite close to the result of uniform excitation. The corresponding response of the common suspended structure was more significant than that of the damping suspended structure, gradually increased with the rise of the apparent wave velocity and reached the maximum when the apparent wave velocity was $800 \mathrm{~m} / \mathrm{s}$. This value was slightly larger than that of uniform excitation.

In Table 6, the amplitude reduction $k$ was $87.30 \sim 93.89 \%$, which showed that the damping suspended structure had a fairly good vibration damping effect.

It can be seen from Figure 9 that when the apparent wave velocity was $500 \mathrm{~m} / \mathrm{s}$, the peak acceleration response of the top suspended floor of the damping suspended structure was much smaller than that of the common suspended structure, the amplitude reduction under the seismic load of all levels was 79.34-93.67\%, and the damping effect was very significant. Among them, the amplitude reduction under the Taft wave reached $88.57 \sim 93.67 \%$. The layout of the viscous damper played an important role, which significantly reduced the acceleration response of the suspended floor. In addition, under different seismic waves, the peak acceleration response of the top suspended floor of the two model structures was different, but whether it was the common suspended structure or damping suspended structure, the model structure had the largest peak acceleration under the artificial wave, which reflected the sensitivity of the structure to different seismic waves.

3.4. Strain Response. The strain response of key parts of the main structure (for example, the bottom of the megaframe column, the end of the hanging beam, and the beam span) was also the focus of this experimental study. Due to a large number of experimental conditions and time history analysis, the data were enormous, and it was not necessary to list them all. Only representative results were given here.

Table 7 shows the mean value of the peak strain response of the column bottom, beam span, and beam end under the action of 9 frequent earthquakes.

It can be seen from Table 7 that the traveling wave effect had an influence on the two suspended structure models, but there were some differences in its effects. As for the common suspended structure, the traveling wave effect increased the strain at the key parts of the structure, which had a more considerable influence on the beam end, followed by the beam span and finally the bottom of the column. Under the uniform excitation of the El Centro wave, the strain of the beam end was 192. If the apparent wave velocity was $800 \mathrm{~m} / \mathrm{s}$, 


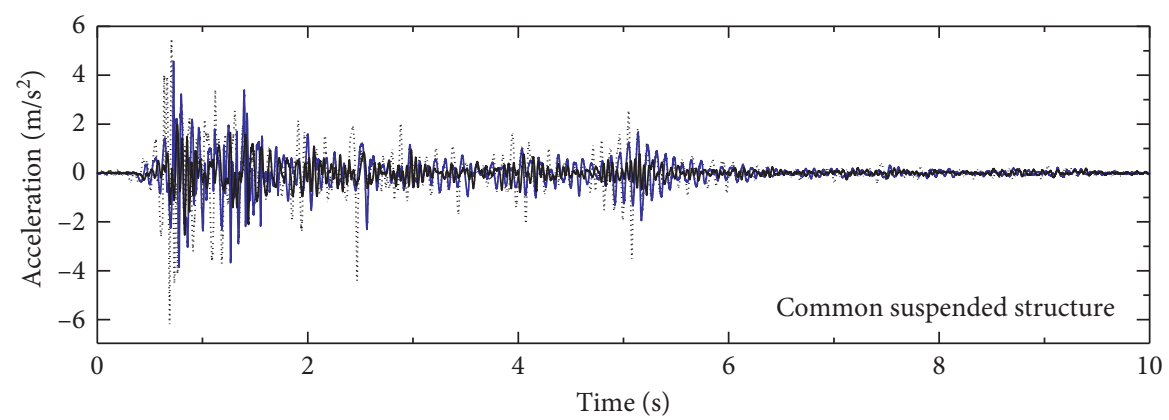

...... Uniform

$-800 \mathrm{~m} / \mathrm{s}$

$-300 \mathrm{~m} / \mathrm{s}$

(a)

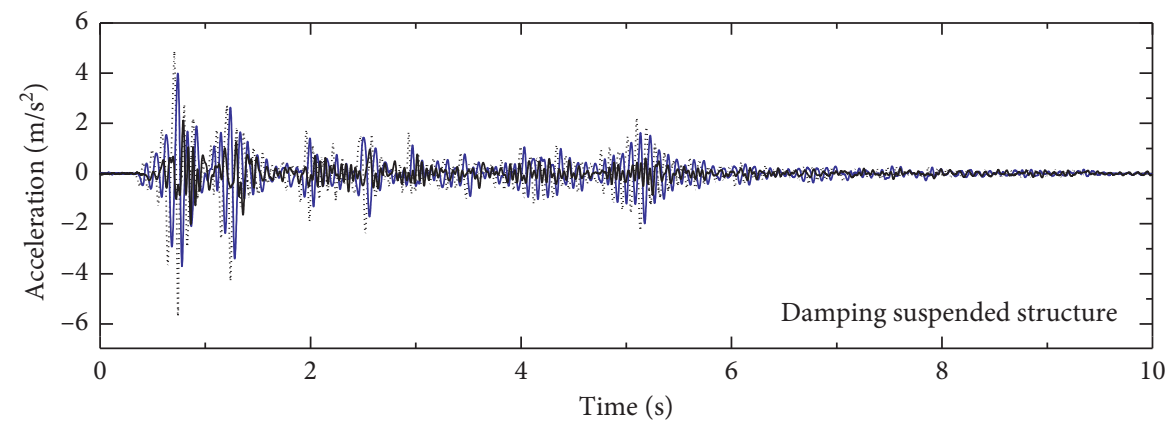

Uniform

$-800 \mathrm{~m} / \mathrm{s}$

$-300 \mathrm{~m} / \mathrm{s}$

(b)

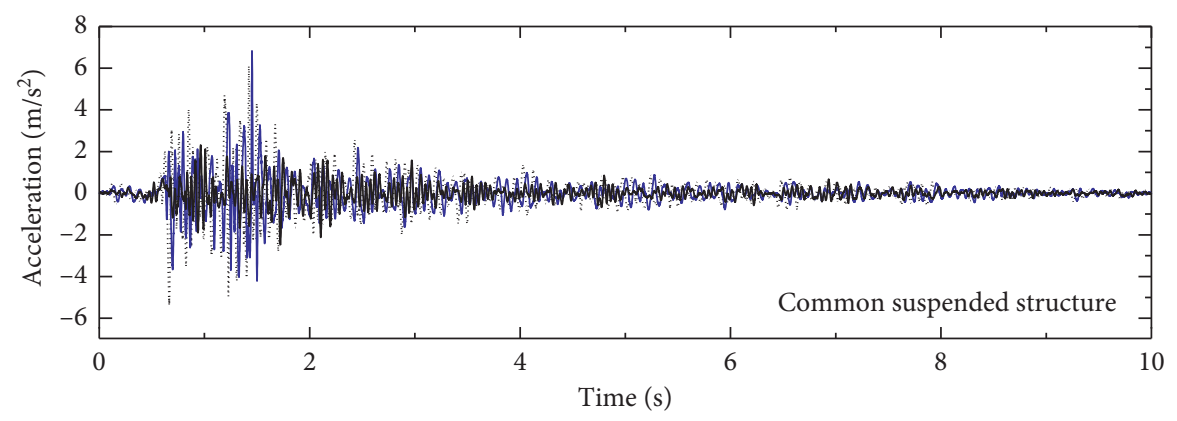

Uniform

$-800 \mathrm{~m} / \mathrm{s}$

$-300 \mathrm{~m} / \mathrm{s}$

(c)

Figure 8: Continued. 


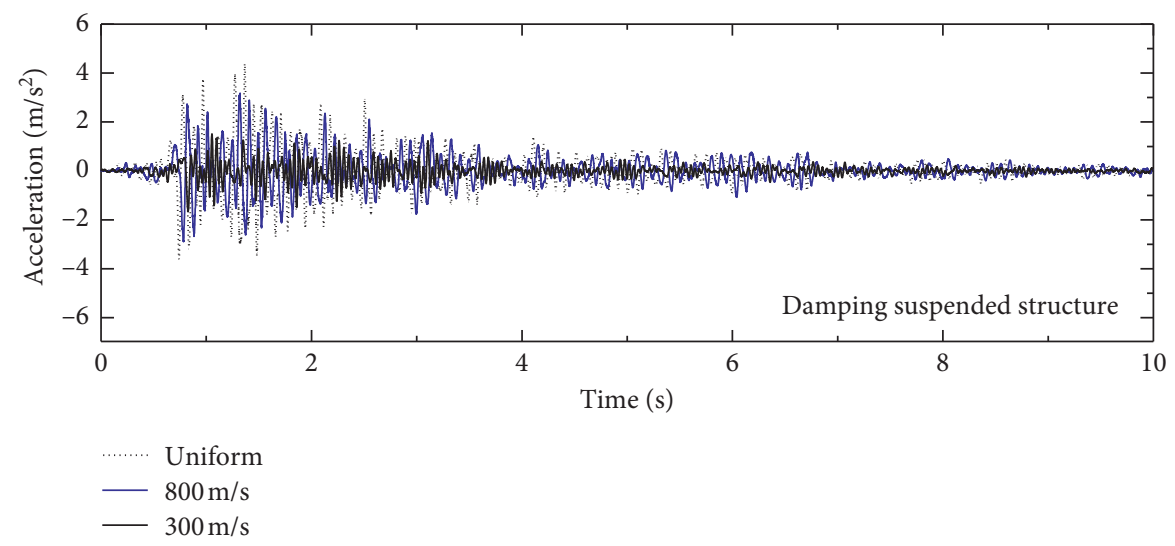

(d)
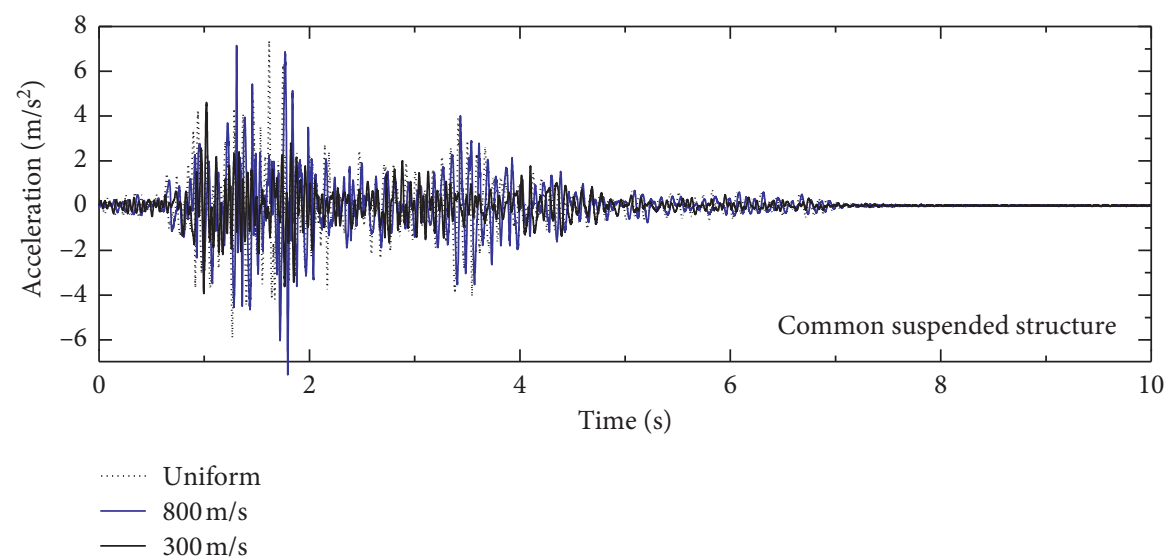

$-300 \mathrm{~m} / \mathrm{s}$

(e)

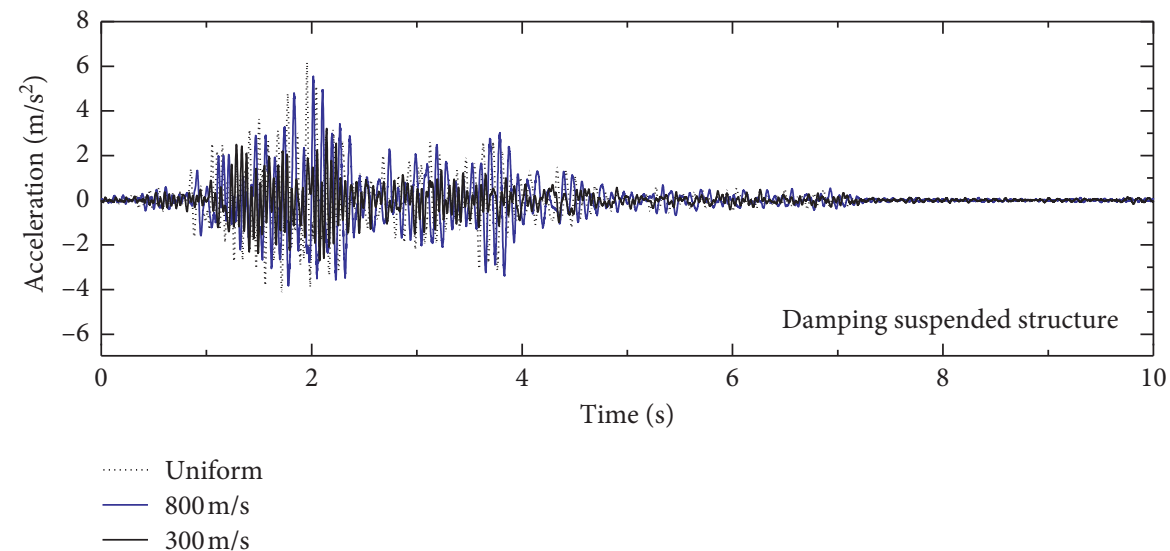

(f)

Figure 8: Acceleration time-history curves at the top of primary structure under 9 frequent earthquakes. (a) Acceleration time history of common suspended structure under El Centro. (b) Acceleration time history of damping suspended structure under El Centro. (c) Acceleration time history of common suspended structure under Taft. (d) Acceleration time history of damping suspended structure under Taft. (e) Acceleration time history of common suspended structure under the artificial wave. (f) Acceleration time history of damping suspended structure under the artificial wave.

it reached 290 with the increase of $51.0 \%$, if the apparent wave velocity was $500 \mathrm{~m} / \mathrm{s}$, the increase was $42.7 \%$, and if the apparent wave velocity was at $300 \mathrm{~m} / \mathrm{s}$, the increase was $3.7 \%$. It can be seen that the apparent wave velocity had a significant influence on the strain at the beam end, and the higher the apparent wave velocity, the greater the influence.
The reason for the analysis may be that when the apparent wave velocity was large, the time difference between the two shaking tables was small, but the asynchronous motion of the support caused the peak response of the structure to be superimposed. However, when the apparent wave velocity was small, the time difference between the two 
TABLE 6: Peak acceleration response of the top suspended floor under 9 frequent earthquakes.

\begin{tabular}{|c|c|c|c|c|c|}
\hline Seismic input & Structure & Uniform excitation & $800 \mathrm{~m} / \mathrm{s}$ & $500 \mathrm{~m} / \mathrm{s}$ & $300 \mathrm{~m} / \mathrm{s}$ \\
\hline \multirow{3}{*}{ El Centro } & Common & 4.902 & 5.148 & 3.546 & 2.307 \\
\hline & Damping & 0.488 & 0.360 & 0.336 & 0.293 \\
\hline & $k$ & $90.04 \%$ & $93.01 \%$ & $90.52 \%$ & $87.30 \%$ \\
\hline \multirow{3}{*}{ Taft } & Common & 5.18 & 5.792 & 3.518 & 2.474 \\
\hline & Damping & 0.427 & 0.354 & 0.317 & 0.244 \\
\hline & $k$ & $91.76 \%$ & $93.89 \%$ & $90.99 \%$ & $90.14 \%$ \\
\hline \multirow{3}{*}{ Artificial wave } & Common & 6.234 & 5.958 & 5.764 & 3.183 \\
\hline & Damping & 0.555 & 0.488 & 0.476 & 0.348 \\
\hline & $k^{\circ}$ & $91.10 \%$ & $91.81 \%$ & $91.74 \%$ & $89.07 \%$ \\
\hline
\end{tabular}

Note: in addition to the \% data added in the above table, the remaining data units are all $\mathrm{m} / \mathrm{s}^{2}$.

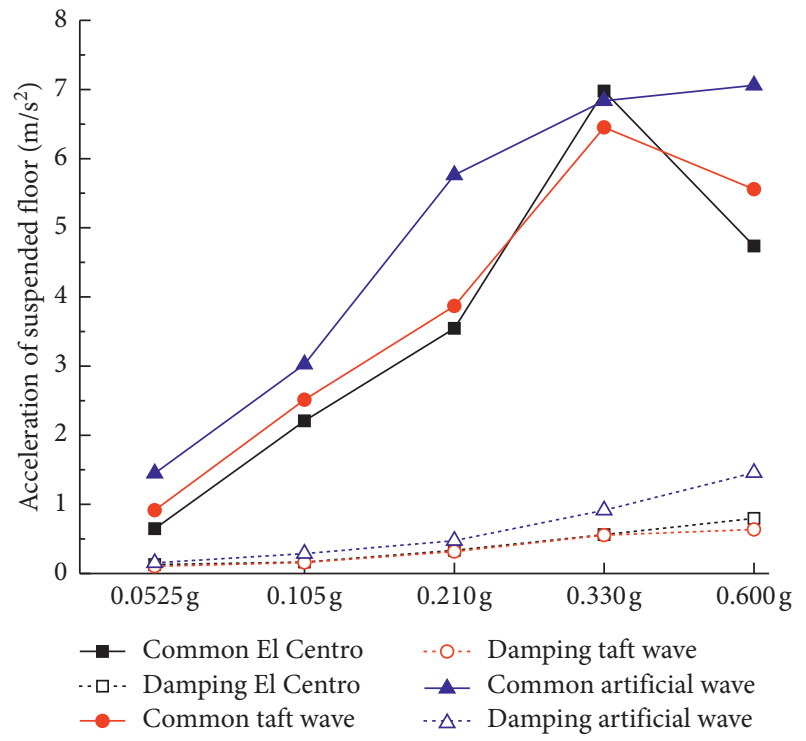

FIGURE 9: Peak acceleration response of the top suspended floor at $500 \mathrm{~m} / \mathrm{s}$ apparent wave velocity.

TABLE 7: Peak strain response of key parts.

\begin{tabular}{|c|c|c|c|c|c|c|c|c|c|}
\hline \multirow{2}{*}{ Case } & \multirow{2}{*}{ Location } & \multirow{2}{*}{ Model } & \multicolumn{7}{|c|}{ Concrete strain $(\mu \varepsilon)$} \\
\hline & & & Uniform & $800 \mathrm{~m} / \mathrm{s}$ & $\alpha$ & $500 \mathrm{~m} / \mathrm{s}$ & $\alpha$ & $300 \mathrm{~m} / \mathrm{s}$ & $\alpha$ \\
\hline \multirow{6}{*}{ El Centro wave } & \multirow{2}{*}{$\mathrm{BC}$} & Common & 154 & 152 & $-1.3 \%$ & 172 & $11.7 \%$ & 150 & $-2.6 \%$ \\
\hline & & Damping & 70 & 72 & $2.9 \%$ & 62 & $-11.4 \%$ & 63 & $-10 \%$ \\
\hline & \multirow{2}{*}{ EB } & Common & 192 & 290 & $51.0 \%$ & 274 & $42.7 \%$ & 199 & $3.7 \%$ \\
\hline & & Damping & 68 & 93 & $36.8 \%$ & 68 & 0 & 70 & $2.9 \%$ \\
\hline & \multirow{2}{*}{$\mathrm{MB}$} & Common & 60 & 56 & $-6.7 \%$ & 52 & $-13.3 \%$ & 43 & $28.3 \%$ \\
\hline & & Damping & 31 & 36 & $16.1 \%$ & 30 & $-3.2 \%$ & 33 & $6.5 \%$ \\
\hline \multirow{6}{*}{ Taft wave } & \multirow{2}{*}{$\mathrm{BC}$} & Common & 161 & 184 & $14.3 \%$ & 167 & $3.7 \%$ & 154 & $-4.4 \%$ \\
\hline & & Damping & 78 & 43 & $-44.9 \%$ & 76 & $-2.6 \%$ & 79 & $1.3 \%$ \\
\hline & \multirow{2}{*}{ EB } & Common & 194 & 285 & $46.9 \%$ & 255 & $31.4 \%$ & 224 & $15.5 \%$ \\
\hline & & Damping & 53 & 67 & $26.4 \%$ & 63 & $18.9 \%$ & 54 & $1.9 \%$ \\
\hline & \multirow{2}{*}{$\mathrm{MB}$} & Common & 52 & 55 & $5.8 \%$ & 58 & $11.5 \%$ & 58 & $11.5 \%$ \\
\hline & & Damping & 30 & 33 & $10 \%$ & 29 & $-3.3 \%$ & 30 & 0 \\
\hline \multirow{6}{*}{ Artificial wave } & \multirow{2}{*}{$\mathrm{BC}$} & Common & 166 & 318 & $91.6 \%$ & 303 & $82.5 \%$ & 200 & $20.5 \%$ \\
\hline & & Damping & 87 & 80 & $-8.1 \%$ & 81 & $-6.9 \%$ & 83 & $-4.6 \%$ \\
\hline & \multirow{2}{*}{$\mathrm{EB}$} & Common & 176 & 234 & $33.0 \%$ & 202 & $14.8 \%$ & 194 & $10.2 \%$ \\
\hline & & Damping & 95 & 87 & $8.4 \%$ & 83 & $-12.6 \%$ & 83 & $-12.6 \%$ \\
\hline & \multirow{2}{*}{$\mathrm{MB}$} & Common & 49 & 53 & $8.2 \%$ & 62 & $26.5 \%$ & 69 & $40.8 \%$ \\
\hline & & Damping & 26 & 27 & $3.9 \%$ & 28 & $7.7 \%$ & 24 & $-7.7 \%$ \\
\hline
\end{tabular}

Note 1: the "BC" indicates the bottom of the column, the "EB" indicates the ends of the hanging beam, and the "MB" indicates the midspan of the hanging beam. Note 2: a negative $\alpha$ in the above table indicates that the value is a negative increase, i.e., the actual value is reduced. 
shaking tables was large, and the asynchronous movement of the support constrained the seismic acceleration response of the suspended floors by rigid damping, so that the suspended floors with rigid connection had the minimum seismic acceleration response at an apparent wave velocity of $300 \mathrm{~m} / \mathrm{s}$. For the damping suspended structure, there were more negative increases in Table 5. For example, under artificial waves, when the apparent wave velocities were $800 \mathrm{~m} / \mathrm{s}, 500 \mathrm{~m} / \mathrm{s}$, and $300 \mathrm{~m} / \mathrm{s}$, the strain which increased at the bottom of the column was $-8.1 \%,-6.9 \%$, and $-4.6 \%$, respectively. Under some conditions, there was also a positive increase, but the increase was significantly smaller than the common suspended structure. It was shown that even at different apparent wave speeds, the damping suspended structure still had a good damping effect, which was beneficial to the stress of the key parts of the structure. At this time, the influence of the traveling wave effect on the strain response of the column bottom could be ignored.

\section{Conclusions}

Through the shaking table test study on the damping suspended structure and the common suspended structure, the seismic response of the two model structures considering the traveling wave effect under different apparent wave velocities was analyzed and compared with the seismic response under the uniform excitation. The following conclusions can be drawn:

The damping ratio of the damping suspended structure was significantly larger than that of the common suspended structure. The first three-order natural frequencies of the damping suspended structure were significantly smaller than those of the common suspended structure, especially the first order.

Under the different apparent wave velocity and uniform excitation, the top displacement peak response of the damping suspended structure is lower than that of the common suspended structure, and the amplitude reduction is $0.83 \% \sim 15.74 \%$.

The relative displacement between the suspended floor and the main structure of the damping suspended structure was significantly larger than that of the common suspended structure. Under different apparent wave velocities, there was no apparent regularity to the relative displacement between primary and secondary structures.

With the increase of the apparent wave velocity, the maximum acceleration response of the top suspended floor of damping suspended structure gradually increases and is quite close to the uniform excitation. The corresponding response of the common suspended structure is significantly larger, increases with the rise of the apparent wave velocity, and reaches the maximum when the apparent wave velocity is $800 \mathrm{~m} / \mathrm{s}$. At each apparent wave velocity, the top acceleration response of the two model structures lags behind the uniform excitation slightly, and the smaller the apparent wave velocity, the more obvious the hysteresis phenomenon.

The strain at the key part of the damping suspended structure has significantly smaller growth than the common suspended structure under different apparent wave velocities, and the influence of traveling wave effect on structural strain response can be ignored.

\section{Data Availability}

The data used to support the findings of this study are included within the article.

\section{Conflicts of Interest}

The authors declare that they have no conflicts of interest.

\section{Acknowledgments}

This work was supported by the National Natural Science Foundation of China (grant numbers: 51508491 and 51478408) and Scholarship for Overseas Studies in Yancheng Institute of Technology.

\section{References}

[1] C. Nutti and I. Vanzi, "Influence of earthquake spatial variability on differential soil displacements and SDF system response," Earthquake Engineering and Structure Dynamics, vol. 34, no. 11, pp. 1353-1374, 2005.

[2] A. A. Dumanogluid and K. Soyluk, "A stochastic analysis of long span structures subjected to spatially varying ground motions including the site-response effect," Engineering Structures, vol. 25, no. 10, pp. 1301-1310, 2003.

[3] M. Xiong, Y. Huang, and Q. Zhao, "Effect of travelling waves on stochastic seismic response and dynamic reliability of a long-span bridge on soft soil," Bulletin of Earthquake Engineering, vol. 16, no. 9, pp. 3721-3738, 2018.

[4] S. Adanur, A. C. Altunışık, H. B. Başağa, K. Soyluk, and A. A. Dumanoğlu, "Wave-passage effect on the seismic response of suspension bridges considering local soil conditions," International Journal of Steel Structures, vol. 17, no. 2, pp. 501-513, 2017.

[5] H. Wang, J. Li, T. Tao, C. Wang, and A. Li, "Influence of apparent wave velocity on seismic performance of a superlong-span triple-tower suspension bridge," Advances in Mechanical Engineering, vol. 7, no. 6, pp. 1-14, 2015.

[6] N. M. Apaydin, S. Bas, and E. Harmandar, "Response of the fatih sultan mehmet suspension bridge under spatially varying multi-point earthquake excitations," Soil Dynamics and Earthquake Engineering, vol. 84, pp. 44-54, 2016.

[7] R. Wang and L. Xu, "Earthquake response analysis with travelling-wave for a long-span steel truss-arch railway bridge," Advances in Structural Engineering, vol. 16, no. 8, pp. 1365-1370, 2013.

[8] M. Akkose, "Arrival direction effects of travelling waves on nonlinear seismic response of arch dams," Computers and Concrete, vol. 18, no. 2, pp. 179-199, 2016.

[9] Z. Chen, Bo Zhao, and Y. Wang, "Seismic response analysis of large-span cable supported barrel vault to multi-support excitations," China Civil Engineering Journal, vol. 47, pp. 59-64, 2014.

[10] J. Ye, Z. Zhang, and Y. Chu, "Strength behavior and collapse of spatial-reticulated structures under multi-support excitation," Science China Technological Sciences, vol. 54, no. 6, pp. 1624-1638, 2011.

[11] L. Xu and J. Ye, "DEM algorithm for progressive collapse simulation of single-layer reticulated domes under multi- 
support excitation," Journal of Earthquake Engineering, vol. 23, no. 1, pp. 18-45, 2019.

[12] H. Yu, X. Yan, A. Bobet, Y. Yuan, G. Xu, and Q. Su, "Multipoint shaking table test of a long tunnel subjected to nonuniform seismic loadings," Bulletin of Earthquake Engineering, vol. 16, no. 2, pp. 1041-1059, 2018.

[13] A. M. Thomas, Z. Spica, M. Bodmer, W. H. Schulz, and J. J. Roering, "Using a dense seismic array to determine structure and site effects of the two towers earthflow in Northern California," Seismological Research Letters, vol. 91, no. 2, pp. 913-920, 2020.

[14] W. Lin, S. H. Chen, J. X. Yu, and A. Qi, "Seismic behavior of long-span connected structures under multi-supported and multi-dimensional earthquake excitations," Advances in Structural Engineering, vol. 16, no. 9, pp. 1579-1586, 2013.

[15] N. Merve Caglar and S. Erdal, "Application of travelling wave method for dynamic analysis of plane frame structures," Bulletin of Earthquake Engineering, vol. 17, no. 3, pp. 13611377, 2019.

[16] X. Xu, B. Guo, and K. Lu, "Suspended structure-a new green form," Ecological and Intelligent Building, vol. 39, no. 3, pp. 53-55, 2009.

[17] W. Schueller, High-rise Building Structures, John Wiley \& Sons, New York, NY, USA, 1977.

[18] B.-J. Yu and W.-H. Cai, "Analysis of the damping performance for semi-rigid suspended damping structure," in Proceeding of Third International Conference on Information and Computing, Wuxi, China, June 2010.

[19] W. Cai, B. Yu, and S. Kaewunruen, "Shaking table tests of suspended structures equipped with viscous dampers," Applied Sciences, vol. 9, no. 13, pp. 2616-2631, 2019.

[20] C. Wang, Z. Lü, and Y. Tu, "Dynamic responses of core-tubes with semi-flexible suspension systems linked by viscoelastic dampers under earthquake excitation," Advances in Structural Engineering, vol. 14, no. 5, pp. 801-813, 2011.

[21] Z. Li, X. Jian, L. Xie, and Z. Qin, "Conceptual design and ANSYS analysis on suspended floor damping system under seismic circumstance," in Proceedings of the 3rd Annual Congress on Advanced Engineering and Technology, Hong Kong, China, October 2016.

[22] B.-J. Yu and W.-H. Cai, "Time history analysis of pulsating wind vibration for semi-rigid mega-frame suspended structure," in Proceedings of the 4th International Conference on Information and Computing, Phuket, Thailand, April 2011.

[23] JGJ3-2010, Technical Specification for Concrete Structures of Tall Building, Ministry of Housing and Urban-Rural Development of the People's Republic of China, Beijing, China, 2010.

[24] GB50011-2010, Code for Seismic Design of Buildings, Ministry of Housing and Urban-Rural Development of the People's Republic of China, Beijing, China, 2010.

[25] JGJ/T101-2015, Specification for Seismic Test of Buildings, Ministry of Housing and Urban-Rural Development of the People's Republic of China, Beijing, China, 2015.

[26] Z. Li, Theory and Technique of Engineering Structure Experiments, Tianjin University Press, Tianjin, China, 2004.

[27] G. Zhang, Bridge Structure Test, China Communications Press, Beijing, China, 2002.

[28] Z. Lu, X. Lu, W. Lu, and S. F. Masri, "Shaking table test of the effects of multi-unit particle dampers attached to an MDOF system under earthquake excitation," Earthquake Engineering \& Structural Dynamics, vol. 41, no. 5, pp. 987-1000, 2012. 